\title{
Das Schillerporträt von Gerhard v. Kügelgen.
}

Während über die unserem Hefte beigegebene Silhouette: „Schiller als Karlsschüler" nichts weiter zu sagen ist, als dass sie den werdenden grossen Mann ausgezeichnet charakterisiert und insofern zu meinem Quellenfund aus Schillers akademischen Jahren eine höchst willkommene Illustrierung bietet - muss ich mich über das v. Kügelgen'sche Bild etwas weiter auslassen.

Dieses Schillerbild war viele Jahrzehnte hindurch nur durch einen mangelhaften Stich von Anderloni bekannt: Das Original blieb trotz allen Suchens verschollen.

Da sind nun vor einigen Jahren fast gleichzeitig zwei Originale des Bildes aufgetaucht. Dass es zwei Originale sind, daran ist zunächst nichts Merkwürdiges: die Künstler jener Zeit machten von ihren Porträtbildern sehr häufig mehrere Ausführungen: es geschah das damals häufiger als heute, aus dem naheliegenden Grunde, weil ja jetzt die Reproduktionstechnik so vollendet ist, dass Wiederholungen durch den Künstler selbst nicht mehr so notwendig sind. So hat z. B. Kügelgen selbst ein und dasselbe Goetheportrat drei- bis viermal mit kaum merklichen Variationen gemalt; dasselbe ist der Fall mit Raabes und Jagemanns Goethebildern.

Das Eine jener Originale des v. Kügelgenschen Schillerbildes war nun im Besitze der Herzogin Friederike von Anhalt-Bermburg (geborene Prinzessìn von Schleswig-Holstein) gewesen. Sie hatte es in ihrer Sommerresidenz Alexisbad im Harz in ihrem daselbst befindlichen 'Schlösschen aufbewahrt. Die hohe Frau, welche hochbetagt im Jahre 1902 gestorben ist, kannte den Wert des Bildes, dessen besondere Schonung sie ihren Dienern stets aufgetragen hatte. Nach ihrem Tode fiel das Schlösschen Alexisbad mit all seinem Inhalt an einen Prinzen von Schleswig-HolsteinAugustenburg. Durch Nachlässigkeit der Hofbeamten, welche den Wert des Bildes nicht erkannten, wurde nun das Schillerbild (nebst einem dazugehörigen Goethebild Kügelgens als Pendant) an einen Privatmann im Harz um einen unglaublich geringen Preis verkauft, wie das ahnlich auch mit einer Reihe anderer wertvoller alter Gegenstände geschah. Der betreffende Privatmann erkannte zwar auch noch nicht sogleich, um was es sich handelte, aber er hatte als gebildeter Mann soviel Einsicht, um wenigstens auf den ersten Blick zu erkennen, dass er ein wertvolles Stück erworben hatte. Er reiste mit dem Bilde nach Dresden und Leipzig, und da wurde dann durch Professor Dr. Julius Vogel, Konservator am Leipziger Museum, festgestellt, dass es sich um ein Kügelgen'sches Original handelte. Professor Vogel liess nun das Bild in der Leipziger Illustrierten Zeitung vom 11. Dezember 1902 reproduzieren nebst einem Begleitartikel. Natürlich wurde diese Reproduktion sehr viel beachtet. Auch jener Prinz wurde nun aufmerksam auf das seltene Stück, das,ihm entgangen war. Ein Rückkaufsversuch scheiterte an der hohen Forderung des neuen glücklichen Besitzers. So ist diese Bildergeschichte wieder eine 
drastische Illustration zu dem bekannten Erfahrungssatze, dass Bilder oft die merkwürdigsten Schicksale haben. Es gilt nicht nur der Satz: Habent sua fata libelli: es gilt auch: Habent sua fata fabellae.

Auch das zweite Original des v. Kügelgenschen Schillerbildes hat ahnliche Schicksale gehabt. Vor einigen Jahren hing es hier in Halle in einem Laden zum allgemeinen Verkaufe aus. Hunderte sahen das Bild und Niemand nahm es: der Preis war, wenn auch nicht so gering wie beim Alexisbader Bilde, so doch mässig. Der Zufall futhrte mich in den Laden und ich erwarb das Bild, und rettete es damit vor der Verschleuderung. Über den Vorbesitzer, nach dem ich mich natürlich sogleich erkundigte, konnte ich nur erfahren, dass das Bild aus dem Besitz einer verarmten Anhaltinischen Adelsfamilie stammte, deren Name mir aber aus naheliegenden Grïnden verschwiegen wurde.

Ich gab nun der Firma E. A. Seemann in Leipzig auf ihre Bitte hin die Erlaubnis, von meinem Bilde eine Reproduktion in Dreifarbendruck zu veranstalten und dieselbe dem in ihrem Verlag erschienenen Werke von Karl Heinemann "Goethe“ (dritte Auflage 1903) beizulegen (S. 474). Hierdurch wurde nun das Bild in seinem wunderbaren Farbenreiz dem gebildeten Publikum zum ersten Male vorgeführt. Eine zweite, ebenfalls farbige Reproduktion des Bildes (aber durch eine andere Kunstanstalt) hat nun soeben mit meiner Erlaubnis die Firma George Westermann in Braunschweig veranstaltet, indem sie das Bild in ihrem Maiheft 1905 ihrem Schillerfestartikel von Otto Harnaok beifügte. Die unserem eigenen Schillerfesthefte beigelegten Exemplare in Dreifarbendruck stammen zum Teil von der Firma E. A. Seemann, zum anderen Teil von der Firma G. Westermann.

Aus den obigen Mitteilungen ersieht man nun wieder aufs Neue, welchen wunderbaren Schicksalen Bilder im Privatbesitz ausgesetzt sirid. Aber nicht immer führen diese Schicksale zu solch erfreulichem Ende. Die Bilder sind im Privatbesitz mancherlei Fährlichkeiten ausgesetzt: sie können durch Unachtsamkeit und selbst ohne Schuld leicht verdorben werden, und sie können im Erbgang nach einigen Generationen leicht verschleudert werden. Ebenso schlimm ist es, wenn sie ins Ausland verkauft werden. Bei den enormen Preisen, welche in Frankreich, England und Amerika von Liebhabern bezahlt werden, ist diese Gefahr sogar sehr drohend: wie viel wertvolles Gut ist aus Deutschland in den letzten Jahren über den Ocean gewandert in die Hände amerikanischer Milliardäre. Ich habe auf einen solchen Verkauf an Privathesitzer verzichtet: solche Bilder, wie ein Kügelgen'sches Schillerbild, sind Eigentum der Nation und sollen allen zugänglich sein.

Ich freue mich daher, hier die Mitteilung hinzufügen $\cdot z u$ können, dass Scine Majestät der König von Württemberg das bisher in meinem Besitz befindliche Bild erworben hat, um es dem Schillermuseum in Marbach zum 9. Mai zum Geschenk zu machen

H. Vaihinger. 